\title{
Antidiabetic Effects of Scrophularia Striata Ethanolic Extract Via Suppression of Pdx1 And Ins1 Expression In Pancreatic Tissues of Diabetic Rats
}

\author{
Armieti Babaiedarzi \\ Islamic Azad University \\ Saba Ghanbari \\ Islamic Azad University \\ Maryam Mehrad seresht \\ Islamic Azad University \\ Modara Nasiri ( $\square$ modara.nasiri@gmail.com ) \\ Islamic Azad University
}

\section{Research Article}

Keywords: Diabetes, Ins1 gene, pancreas, Pdx1 gene, Scrophularia striata.

Posted Date: January 24th, 2022

DOI: https://doi.org/10.21203/rs.3.rs-1151931/v1

License: (a) (i) This work is licensed under a Creative Commons Attribution 4.0 International License.

Read Full License

Version of Record: A version of this preprint was published at Scientific Reports on June 13th, 2022. See the published version at https://doi.org/10.1038/S41598-022-13698-W. 


\section{Abstract}

Background: Diabetes mellitus (DM) is a pathological disease that results in severe metabolic imbalances and abnormal changes in many tissues, especially in the pancreas, where oxidative stress plays an important role in etiology. Therefore, the therapeutic effects of Scrophularia striata were investigated using an animal model in the control of diabetic injury and pancreatic complications caused by diabetes.

Methods: A total of 66 rats (weight $220-250 \mathrm{~g}$ ) were randomly divided into: Healthy Control group; Diabetic control group; 3 experimental healthy groups; 3 treatment groups; and3 pretreatment groups. Diabetes was induced in rats by intraperitoneal STZ $(60 \mathrm{mg} / \mathrm{kg} \mathrm{bw})$. FBS, HbA1c and insulin were measured after four weeks. $P d x 1$ and Ins1 gene expression was assessed by RT-PCR. The histological evaluation was also performed with H\&E staining. The data were analyzed by SPSS ver20 using ANOVA and Tukey tests.

Results: By treatment with $S$. striata ethanolic extract, these factors were close to the normal range. The expression of the $P d x 1$ and Ins1 genes increased in the treated rats after treatment with $S$. striata extract.

Conclusions: Therefore, by improving serum indexes and $P d x 1$ and Ins 1 gene expression, S. striata may be used as adjuvant therapy for complications of diabetes.

\section{Introduction}

One of the oldest known disorders is diabetes mellitus (DM) in humans. It is assumed that DM due to the inherent stresses of modern lifestyles and the increasing prevalence of diabetes is becoming a major public health problem affecting millions of people worldwide. According to the World Health Organization (WHO), by 2025, 300 million people will have diabetes. Diabetes mellitus is a pathological disease, and as a result causes severe metabolic imbalances and abnormal changes in many tissues, especially in the pancreas, where an important role in etiology is played by oxidative stress. High oxidative stress because of persistent and chronic high blood sugar is tested in diabetic and experimental animal models, thus destroying the activity of the antioxidant defense system and thereby producing free radicals [1-3]. In diabetes mellitus, changes in the defense mechanisms of endogenous free radical scavenging may lead to ineffective inhibition of oxygen-reactive species, leading to oxidative damage and tissue damage. Tissue damage has been suggested and streptozotocin acts as a diabetic agent due to its ability to destroy pancreatic $\beta$-cells, possibly by the mechanism of free radicals $[4,5]$.

The pancreas is the synthesis, storage and secretion site of insulin. In the pancreatic islets, there is a complex signaling cascade for the secretion of glucose-stimulating insulin that includes ATP-sensitive potassium channels ( $\mathrm{K}_{\text {ATP }}$ ). In the presence of glucose, an increase in the intracellular ATP/ADP ratio causes the $\mathrm{K}_{\text {ATP }}$ channels to close, resulting in the plasma membrane depolarization, extracellular calcium influx, and exocytosis activation. The cell plasma membrane islet has $\mathrm{K}_{\text {ATP }}$ channels, although 
most $\mathrm{K}_{\text {ATP }}$ channels are located on secretory granule membranes. The $\mathrm{K}_{\text {ATP }}$ channels of pancreas have four sulfonylurea-regulating receptor subunits (SUR1) and four potassium pore-formation subunits $\left(\mathrm{K}_{\mathrm{ir}} 6.2\right)$ [6]. One of the chronic autoimmune diseases is type 1 diabetes (T1D) in which insulin-producing beta-cells in the pancreas are destroyed, resulting in chronic high blood sugar. Pancreatic exocrine abnormalities have been described in recent decades in terms of anatomy and function. It is not clear whether exogenous changes of in T1D are relevant to identical genetic, immunological, and environmental events that lead to the destruction of beta-cells and are secondary to functional $\beta$ cell loss. Therefore, insulin acts as a trophic agent for the exocrine compartment [7].

The main goal of caring for diabetic patients is to minimize the risk of microvascular and macrovascular complications by returning blood pressure, and lipid and glycemic profiles to normal. The particular aim for glycemic control is to reach glycated hemoglobin $\left(\mathrm{HbA}_{1 \mathrm{c}}\right)$ to a normal range because good glycemic control is important to decrease the long-term microvascular complication risk in both type 1 and 2 diabetes [8]. HbA1c can be measured at any time of the day, regardless of the duration of the fast or the content of the previous meal. It can also be analyzed using a portable device with a small blood sample [9]. Glycated hemoglobin (HbA1c) analysis in blood enables evidence of a person's average blood glucose level over the past two to three months, which is the red blood cell (RBC) half-life [10].

There is ample evidence that $\beta$-cell regeneration and function in the adult pancreas are mediated partly by pancreatic and duodenal homeobox $1(P d x 1)$, and that changes in expression are associated with the alterations in the expression of target genes, including insulin 1 (Ins1) [3]. Pdx1 is an important transcription factor needed for pancreatic development and maintains the distinctive function of $\beta$-cells, especially the regulation of normal glucose-insulin secretion $[11,12]$. The first transcription factor produced in the growing pancreas is $P d x 1$, and lack of this factor causes pancreatic agenesis because of the inability to generate a variety of duct, exocrine or endocrine cells. Conditional elimination of $P d x 1$ from $\beta$ cell formation by insulin Cre lines leads to hyperglycemia $[13,14]$. Previous studies have shown that $P d x 1$ plays a major role in diabetes and that reducing the expression of $P d x 1$ exacerbates diabetes $[15,16]$.

Scrophularia striata, known as "Teshnedari" from the Scrophulariaceae family, is one of the most important herbal medicines that is widely used in western Iran. This herb is an annual or perennial plant that has a zygomorphic flower and 5 petals flower, and the calyx has lobes and its fruit is a capsule with many seeds. It has been reported that Scrophularia striata has some medicinal effects including analgesic, antimicrobial, nephrotic, nitric oxide suppressant, antitumor, hepatic protection and antiinflammatory effects [17-20]. Due to the medicinal effects of Scrophularia striata plants and their side effects, they have not been studied thus far. In this study, using an animal model, the effects of this plant were investigated in preventing diabetes-induced damage to the pancreas and its functions.

\section{Material And Methods}

\section{Ethics statement}


All animal maintenance and procedures were in accordance with recommendations established by the Animal Ethics Committee of the Islamic Azad University, North Tehran Branch, as well as the United States NIH guidelines (publication no. 85-23). The Ethics Committee approved the protocols of The Islamic Azad University, North Tehran Branch. All surgical procedures were carried out beneath deep anesthesia, and all efforts had been made to minimize suffering. (ethical code:

IR.IAU.TNB.REC.1400.552.). The study is reported in accordance with ARRIVE guidelines (https://arriveguidelines.org).

\section{Animals}

In this study, 66 Wistar rats were purchased in the weight range of 180-330 grams from Pasteur Institute, Tehran, Iran. They were transferred to the Laboratory Animal Breeding Center of North Tehran Azad University. The animals were kept in a laboratory animal breeding center with fiberglass cages $(15 \times 30 \times 35$ $\mathrm{cm})$ and a $12 \mathrm{~h}$ light/ $12 \mathrm{~h}$ dark cycle and temperature $\left(22 \pm 2{ }^{\circ} \mathrm{C}\right)$, light with a relative humidity range of 40-60\%. The rats were fed particular food obtained from Behparvar Company, Tehran, Iran. Tap water was used to maintain hydration, and the experimental tubes were used in each cage as their water supply with sufficient water and food during the experiment. All research and laboratory animal care were performed by responding to the Guide for the Care and Use of Laboratory Animals (National Research Council, 2012). When their weight reached $220-250 \mathrm{~g}$, the experiment was started.

\section{Selection of Diabetic Rats by inducing Streptozotocin}

Streptozotocin (STZ; Sigma Aldrich, USA) was used to induce diabetes. STZ was dissolved at a dose of $60 \mathrm{mg} / \mathrm{kg}$ body weight and injected intraperitoneally into rats. Blood glucose was monitored $48 \mathrm{~h}$ after STZ injection. To measure the inactive serum glucose level glucometer tapes were used on the rat tail vein. If the measured blood glucose was higher than $300 \mathrm{mg} / \mathrm{dl}$, we considered diabetic rats [21].

\section{Preparation of Scrophularia striata ethanolic extract}

Scrophularia striata (Teshnedari) is a regional plant that was collected from highlands of the Zagros mountain chain, Ilam, Iran. Considering that the floral part of the plant is used to obtain the extraction, this plant is collected in spring. It was identified at the Traditional and Complementary Medicine Research Center, Tehran University of Medical Sciences, Tehran, Iran. Dehydration is the primary step of all the steps of plant preparation for extraction. After collection, the plants needed to be cleaned with water even before the dehydration step. Then, the soaking method was used to extract the plant material. The soaking method was performed twice to ensure efficient extraction of the material. Every 200 grams of dried Scrophularia striata received $400 \mathrm{ml}$ of ethyl alcohol (Merck, Germany), and their mixture was placed in darkness for 72 hours. The mixture was passed through filter paper three times. After the last filtering stage, it was placed in a dark place to slowly evaporate the alcohol. The dried extract was stored at $0-4{ }^{\circ} \mathrm{C}$. Finally, the dried extract was dissolved in the normal saline to obtain the required doses (100$400 \mathrm{mg} / \mathrm{kg}$ ) [20].

\section{Experimental Design}


The rats were randomly divided into 11 groups ( $n=6$ : healthy control group (receiving propylene glycol which is the solvent of the extracted medicine as solvent); diabetic control group (induced streptozotocin); three experimental healthy groups (receiving the extract at 100, 200 and $400 \mathrm{mg} / \mathrm{kg}$ bw/day), three experimental treatment groups (receiving the extract at 100, 200 and $400 \mathrm{mg} / \mathrm{kg} \mathrm{bw} /$ day), and three pretreatment groups (receiving the extract at 100, 200 and $400 \mathrm{mg} / \mathrm{kg} \mathrm{bw} /$ day). In this experiment, the pretreatment groups were healthy at the beginning of the experiment. In the pretreatment groups, daily gavage was performed with solvent for 2 weeks before and after STZ injection at 3 specified doses. The other groups also underwent daily gavage with the extract solution and solvent for 4 weeks.

\section{Dissection and pancreas sample collection}

After completing four weeks of medication for all the groups, the rats in each group were dissected with a heart under anesthesia, blood was taken directly from their hearts and then centrifuged. Blood samples were collected with a cardiac puncture, to measure some biochemical factors including fasting blood sugar (FBS), hemoglobin A1c ( $\mathrm{HbA} 1 \mathrm{c})$, and insulin; the serum was separated quickly, and then were aliquoted and stored at $-70^{\circ} \mathrm{C}$. Additionally, the pancreatic tissues were fixed in $10 \%$ formalin for histopathological examination.

\section{Histological assessment of pancreas tissue}

On the dissection day, the rat was fasted for 12 hours to anesthetize with ether. Cross-sections of all pancreas lobes were collected, fixed in coded jars containing formaldehyde buffer solution, and then embedded in paraffin. Sections $5 \mu \mathrm{m}$ in size were stained with hematoxylin and eosin (H\&E) and examined by light microscopy. The status of histological damage was considered for atrophy, fibrosis and regeneration status as negative, mild, moderate and severe [22].

\section{Determination of serum FBS, HbA1c and insulin in the studied rats}

After the experimental period, all animals were weighed by on a digital scale, and then anesthetized with ketamine $(622 \mathrm{mg} / \mathrm{kg})$ and xylazine $(62 \mathrm{mg} / \mathrm{kg})$, and blood samples were taken from their hearts. The serum was separated by centrifugation at $10000 \times \mathrm{g}$ for 10 minutes and hemoglobin A1c (HbA1c) was measured by latex enhanced immunoturbidimetric assay with an $\mathrm{HbA1c}$ quantitative detection kit (Pars Azmoon, Tehran, Iran) using a photometric method. Fasting blood sugar (FBS) was measured by a photometric method with a glucose quantity detection kit (GOD-PAP) (Pars Azmoon, Tehran, Iran), and serum insulin was measured by enzyme-linked immunosorbent assay using a Pars Azmoon test kit according to the manufacturer's instructions [23-25].
Assessment of PDX1 and Ins1
quantitative real-time PCR 
Total RNA was extracted from the samples immediately after sampling according to standard protocols using an RNA purification kit (GeneJET ${ }^{\mathrm{rm}}$ RNA Purification Kit \# K0732, Thermo Scientific - Fermentas, Latvia). Total RNA was treated with DNase to remove contaminated genomic DNA using DNase deletion reagents (DNase I, RNase-free (\# EN0521) Fermentas, Latvia), according to the manufacturers' protocol. RNA quality was assessed by agarose gel electrophoresis and UV spectroscopy. The cDNA was synthesized using a first strand transcription cDNA synthesis kit (Thermo Scientific -Fermmentas, Latvia), according to the manufacturers' protocol. After sequencing both $P d x 1$ and Ins 1 gene types and finding specific sequences of the species, the primers were designed by oligo7 software and blasted on the NCBI website. The glyceraldehyde-3-phosphate dehydrogenase (GAPDH) gene was used for normalization as an endogenous reference gene. The primers were $P d x 1$ forward 5'CCTTTCCCGAATGGAACCGA3', $P d x 1$ reverse 5'TTTTCCACGCGTGAGCTTTG3' and Ins 1 forward 5'GTCAAACAGCACCTTTGTGGT3' and Ins 1 reverse 5'AGAAACCACGTTCCCCACAC3'. Agarose gel electrophoresis was used to evaluate the predicted size of the PCR amplitudes of genes. Standard curves for each gene were prepared using serial dilutions (1: 4) of cDNA fused from total RNA extracted from the samples. In each experiment, the value of $\mathrm{R}^{2}$ was the standard curve N0.99, and no-template control experiments resulted in the absence of a detectable signal. Quantitative RT-PCR was performed using SYBR Green (Thermo Scientific Maxima SYBR Green/ROX qPCR Master Mix (2 × ) \# K0221, Thermo Scientific - Fermentas, Latvia). A triplicate method was performed for quantitative real-time PCR using a 7900HT Fast Real-Time PCR System with a Fast 96-week Block Module (Applied Biosystems, Foster City, CA, USA). PCR data were obtained by Sequence Detector Software (SDS version 2.3 Rev C Patch, Applied Biosystems) and quantified by the standard curve method. This software plotted the real-time fluorescence intensity and selected the threshold within the linear phase of the amplicon profile. The software plotted a standard curve of the cycle at threshold versus extracted RNA quantity. Samples were measured in one plate for one target gene and their $C_{t}$ values were in the linear range of the standard curve. In the qPCR test, outliers or sample failures were repeated for each gene. The Pfafle formula is used to calculate the ratio. Quantitative real-time PCR and analysis of expression data were performed based on a previous study [26].

\section{Statistical Analysis}

All data were statistically analyzed by SPSS-20 software. After confirming the normality of the data, oneway analysis of variance (ANOVA-one way) and Tukey's test were performed. The results are presented as the mean \pm S. E. M Statistical inference was used.

\section{Results}

\section{Effects of Scrophularia striata ethanolic extract on FBS, HbA1c and insulin in serum}

According to Graph 1, FBS and HbA1c increased in the sham group compared to the control group. In addition, FBS was significantly reduced in the 400-treatment group compared to the sham and control groups $(\mathrm{P} \leq 0.05)$. On the other hand, $\mathrm{HbA} 1 \mathrm{c}$ index reduced in all the treatment, experimental healthy and pretreatment groups compared to the sham and control groups, which was significant in 200 healthy 
experimental and 100 pretreatment experimental groups $(P \leq 0.05)$. However, insulin decreased significantly in the sham group compared to the control group, and all the treatment and experimental healthy groups increased the insulin index significantly in a dose-dependent manner.

\section{Effects of Scrophularia striata ethanolic extract on $P d x 1$ and Ins1 gene expression}

Gene expression was compared between groups based on $\Delta \Delta$ ct and fold change. According to an analysis of $\Delta \Delta$ ct, when the $\Delta \Delta$ ct value in a group is low gene expression will be higher. In addition to fold change, whatever fold change value in a group is high, therefore gene expression will also be high. As a result, in the sham group, $P d x 1$ and $I n s 1$ gene expression-compared to that in the control group. In all of the other groups, Ins 1 gene expression was increased compared to that in the sham group. Otherwise, $P d x 1$ gene expression just increased in the treatment 400 group compared to the sham group. The effect of $S$. striata was dose-dependent (Table 1).

Table 1. Comparison of PDX1 and Ins1 gene expression in the studied rats

\begin{tabular}{|lll|}
\hline Group & \multicolumn{2}{c|}{ Fold Change } \\
\hline Sham Vs Control & PDX1 \\
\hline Treatment $\mathbf{1 0 0}$ Vs Sham & 0.19 & 5.35 \\
\hline Treatment 200 Vs Sham & 2.85 & 1.27 \\
\hline Treatment 400 Vs Sham & 3.97 & 2.00 \\
\hline Experimental Healthy $\mathbf{1 0 0}$ Vs Sham & 1.85 & 1.01 \\
\hline Experimental Healthy 200 Vs Sham & 2.16 & 1.34 \\
\hline Experimental Healthy 400 Vs Sham & 3.41 & 0.02 \\
\hline Pretreatment 100 Vs Sham & 0.54 & 1.85 \\
\hline Pretreatment 200 Vs Sham & 0.46 & 2.16 \\
\hline Pretreatment 400 Vs Sham & 0.29 & 3.41 \\
\hline
\end{tabular}

\section{Effects of $S$. striata ethanolic extract on histopathology of the pancreas}

Pancreas histopathologic results are shown in Table 2. Histological study showed that the pancreas tissues of the control group had negative atrophy and fibrosis status and regeneration status. The pancreatic tissues in the sham group showed moderate atrophy and fibrosis status and negative regeneration status.

As shown in Fig 1, no significant tissue changes were observed in the sham group (Fig 1. A), which were healthy and experimental healthy groups treated with $400 \mathrm{mg} / \mathrm{kg} \mathrm{S}$. striata extract (Fig 1. C). whereas 
degeneration of Langerhans islet cells was observed the diabetic control group, and some degree of atrophy and fibrosis was seen in the structure of the pancreas (Fig 1. B). In the pretreatment group (400 $\mathrm{mg} / \mathrm{kg}$ S. striata extract), normal ascites conditions were observed Fig 1. D). Finally, in the treatment group (400 mg/kg S. striata extract), the islets of Langerhans in cellularity improved compared to the control group and were somewhat structurally closer to the sham group, which indicates the effectiveness of the treatment (Fig 1. E).

Table 2. Histopathological results in the studied rats

\begin{tabular}{|lll|}
\hline Group & Atrophy \& fibrosis status & Regeneration status \\
\hline Treatment 100 & Negative & Negative \\
\hline Treatment 200 & Negative & Negative \\
\hline Treatment 400 & Negative & Negative \\
\hline Experimental healthy 100 & Negative & Suspicious positive \\
\hline Experimental healthy 200 & Negative & Suspicious positive \\
\hline Experimental healthy 400 & Negative & Suspicious positive \\
\hline Pretreatment 100 & Negative & Negative \\
\hline Pretreatment 200 & Mild & Negative \\
\hline Pretreatment 400 & Negative & Negative \\
\hline Sham & Moderate & Negative \\
\hline Control & Negative & Negative \\
\hline
\end{tabular}

\section{Discussion}

Persistent and chronic hyperglycemia reduces antioxidant defense system activity and therefore causes the production of free radicals. Increased levels of free radicals along with the failure of the natural antioxidant system generally cause cellular dysfunction and death. Oxidative stress is generated in diabetic situations and may be involved in the development of beta-cell dysfunction in the pancreas [27].

Despite numerous studies on the pathogenesis of diabetes mellitus (DM) and new therapeutic strategies in recent years, the molecular mechanisms of DM pathogenesis and the antidiabetic action of drugs remain largely unknown. In the present investigation, STZ diabetic rats fed Scrophularia striata ethanolic extract (at doses of 100, 200 and $400 \mathrm{mg} / \mathrm{kg}$ bw) per day for four consecutive weeks exhibited significant blood glucose and hemoglobin Ac1 ( $\mathrm{HbA} 1 \mathrm{c})$ reductions and increases in blood insulin levels. These observations are in agreement with a study that showed increased blood glucose concentrations in STZhyperglycemic rats compared to control rats [28]. This hypoglycemic potential, in addition to confirming the traditional use of this plant as a blood glucose-lowering agent has been reported in the literature [29]. 
Phytochemical studies on Scrophularia striata have shown the presence of compounds such as flavonoids, cinamic acid, phenylpropanoid, neptrin, flavonoid glycoside, acteoside1, quercetin and phenylpropanoid glycoside [30-32]. However, to date, the biological activity of these compounds has not been reported to have a hypoglycemic effect. Flavonoids are a group of phenolics of secondary plants with strong antioxidant properties. Independent studies have shown that flavonoids have antidiabetic effects [33]. Therefore, the same group of compounds (e.g., flavonoids) is predicted to respond to the antidiabetic and antioxidant properties of $S$. striata. Our results indicated that Scrophularia striata ethanolic extract can produce a dose-dependent stimulation of insulin release in rats.

The effect of hypoglycemia in plants may be because of the presence of insulin-like substances in plants, the stimulation of B cells to produce more insulin, the fiber found in plants at high levels to interfere with the absorption of carbohydrates or the effect of plants regenerative on pancreatic tissue [34-36]. Theoretically, hypoglycemic plants work through various mechanisms, such as modifying insulin sensitivity, increasing glucose-dependent insulin secretion, and stimulating islet regeneration of Langerhans in the pancreas of STZ-induced diabetic rats. In addition, the role of antioxidant compounds in the protection and treatment of diabetes has been remarked upon in various scientific studies. For instance, treating diabetic animals injected with STZ with N-acetyl-L-cysteine (NAC), a known antioxidant, prohibits high blood sugar by reducing oxidative stress and restoring beta-cell function [33]. On the other hand, STZ has been shown to cause selective damage to pancreatic beta-cells [37]. Hence, beta cell insulin content decreased in untreated diabetic control rats; however, in the Scrophularia striata treatment groups, this pancreatic insulin content was augmented.

There is ample evidence that $\beta$-cell regeneration and function in the adult pancreas are mediated partly by pancreatic and duodenal homobox $1(P d x 1)$, and the changes in its expression are associated with alterations in the expression of target genes, including insulin 1 (Ins-1) [3]. In two previous studies, $P d x 1$ and a subset of other major islet-enriched transcription factors were found to be significantly decreased in human diabetes mellitus type 2 (T2DM) islet $\beta$-cells $[38,39]$. In this study, we also indicated that the Scrophularia striata ethanolic extract increased Ins-1 gene expression. The increased expression levels of the $P d x 1$ and Ins 1 genes may be related to the methylation effect of Scrophularia striata in streptozotocin-induced diabetic rats. However, further investigations are needed to evaluate the methylated genes involved in the regeneration of the pancreas by Scrophularia striata administration.

\section{Conclusion}

According to the results of the present study, the antidiabetic effects of the $S$. striata ethanolic extract were confirmed. In addition, it observed that the $S$. striata extract has the effect of reduction in FBS and $\mathrm{HbA1c}$, in addition it has an increasing effect on serum insulin. Moreover, it was observed that the studied extract was effective in the pancreas by increasing $P d x 1$ and $I n s 1$ gene expression. Generally, $S$. striata ethanolic extract, because of its antioxidant properties, can be considered a beneficial medicine in treatment of diabetes and pancreatic tissue complications due to diabetes. Further study of the detailed 
mechanisms is needed. This study has confirmed the other studies about the antidiabetic and protective properties of $S$. striata in diabetes. Therefore, additional studies can confirm these findings.

\section{Declarations}

\section{Acknowledgment}

We thank Mr. Muhammadnajad from Cancer Biology Research Center, Tehran University of Medical Sciences for the pathology test. The authors of this manuscript have no conflicts of interest to declare.

\section{References}

1. Arulselvan, P., \& Subramanian, SP. Beneficial effects of Murraya koenigii leaves on antioxidant defense system and ultra structural changes of pancreatic $\beta$-cells in experimental diabetes in rats. Chem. Biol. Interact. 165, 155-64 (2007).

2. Zhang, W., Welihinda, A., Mechanic, J., Ding, H., Zhu, L., Lu, Y., et al. EGT1442, a potent and selective SGLT2 inhibitor, attenuates blood glucose and HbA1c levels in $\mathrm{db} / \mathrm{db}$ mice and prolongs the survival of stroke-prone rats. Pharmacol. Res. 63, 284-93 (2011).

3. Bahrami, G., Sajadimajd, S., Mohammadi, B., Hatami, R., Miraghaee, S., Keshavarzi, S., et al. Antidiabetic effect of a novel oligosaccharide isolated from Rosa canina via modulation of DNA methylation in Streptozotocin-diabetic rats. DARU J. Pharm. Sci. 1-10 (2020).

4. Oberley, L.W. Free radicals and diabetes. Free Radic. Biol. Med. 5, 113-124 (1988).

5. Jin, L., Xue, H.Y., Jin, L.J., Li, S.Y., Xu, Y.P. Antioxidant and pancreas-protective effect of aucubin on rats with streptozotocin-induced diabetes. Eur. J. Pharmacol. 582, 162-167 (2008).

6. Taylor, C.G. Zinc, the pancreas, and diabetes: insights from rodent studies and future directions. Biometals. 18, 305-312 (2005).

7. Campbell-Thompson, M., Rodriguez-Calvo, T., Battaglia, M. Abnormalities of the exocrine pancreas in type 1 diabetes. Curr. Diab. Rep. 15, 79 (2015).

8. Currie, C.J., Peters, J.R., Tynan, A., Evans, M., Heine, R.J., Bracco, O.L., et al. Survival as a function of HbA1c in people with type 2 diabetes: a retrospective cohort study. The Lancet. 375, 481-489 (2010).

9. Bennett, C., Guo, M., Dharmage, S. HbA1c as a screening tool for detection of type 2 diabetes: a systematic review. Diabet.Med. 24, 333-343 (2007).

10. Sherwani, S.I., Khan, H.A., Ekhzaimy, A., Masood, A., Sakharkar, M.K. Significance of HbA1c test in diagnosis and prognosis of diabetic patients. Biomarker insights. 2016;11:BMI. S38440.

11. Gauthier, B.R., Wiederkehr, A., Baquié, M., Dai, C., Powers, A.C., Kerr-Conte, J., et al. PDX1 deficiency causes mitochondrial dysfunction and defective insulin secretion through TFAM suppression. Cell. Metab. 10, 110-118 (2009). 
12. Yao, X., Li, K., Liang, C., Zhou, Z., Wang, J., Wang, S., et al. Tectorigenin enhances PDX1 expression and protects pancreatic $\beta$-cells by activating ERK and reducing ER stress. J. Biol. Chem. 295, 1297512992 (2020).

13. Gao, T., McKenna, B., Li, C., Reichert, M., Nguyen, J., Singh, T., et al. Pdx1 maintains $\beta$ cell identity and function by repressing an a cell program. Cell. Metab. 19, 259-271 (2014).

14. Kubo, A., Stull, R., Takeuchi, M., Bonham, K., Gouon-Evans, V., Sho, M., et al. Pdx1 and Ngn3 overexpression enhances pancreatic differentiation of mouse ES cell-derived endoderm population. PLoS One. 6, e24058 (2011).

15. Spaeth, J.M., Gupte, M., Perelis, M., Yang, Y.P., Cyphert, H., Guo, S., et al. Defining a novel role for the $\mathrm{Pdx} 1$ transcription factor in islet $\beta$-cell maturation and proliferation during weaning. Diabetes. 66, 2830-2839 (2017).

16. Fujitani, Y. Transcriptional regulation of pancreas development and $\beta$-cell function. Endocr. J. EJ170098 (2017).

17. Ghashghaii, A., Hashemnia, M., Nikousefat, Z., Zangeneh, M.M., Zangeneh, A. Wound healing potential of methanolic extract of Scrophularia striata in rats. Pharm. Sci. 23, 256-263 (2017).

18. Tanideh, N., Haddadi, M.H., Rokni-Hosseini, M.H., Hossienzadeh, M., Mehrabani, D., Sayehmiri, K., et al. The healing effect of scrophularia striata on experimental burn wounds infected to pseudomonas aeruginosa in rat. World J. Plast. Surg. 4, 16 (2015).

19. Mahboubi, M., Kazempour, N., Nazar, A.R.B. Total phenolic, total flavonoids, antioxidant and antimicrobial activities of Scrophularia striata Boiss extracts. Jundishapur J. Nat. Pharm. Prod. 8, 15 (2013).

20. Monsef-Esfahani, H.R., Hajiaghaee, R., Shahverdi, A.R., Khorramizadeh, M.R., Amini, M. Flavonoids, cinnamic acid and phenyl propanoid from aerial parts of Scrophularia striata. Pharm. Biol. 48, 333336 (2010).

21. Jiang, W., Si, L., Li, P., Bai, B., Qu, J., Hou, B., et al. Serum metabonomics study on antidiabetic effects of fenugreek flavonoids in streptozotocin-induced rats. J. Chromatogr. B Biomed. Appl. 1092, 466472 (2018).

22. Shawky, L.M., Morsi, A.A., El Bana, E., Hanafy, S.M. The Biological Impacts of Sitagliptin on the Pancreas of a Rat Model of Type 2 Diabetes Mellitus: Drug Interactions with Metformin. Biology. 9, 6 (2020).

23. Askari, F., Rashidkhani, B., Hekmatdoost, A. Cinnamon may have therapeutic benefits on lipid profile, liver enzymes, insulin resistance, and high-sensitivity C-reactive protein in nonalcoholic fatty liver disease patients. Nutr. Res. 34, 143-148 (2014).

24. Singh, B., Behera, D.D., Mehta, N., Das, S. Hb hope: a rare variant of haemoglobin-forged a rise in HbA1c on immunoturbidimetric assay. Indian. J. Clin. Biochem. 29, 517-519 (2014).

25. Samani, K.G., Farrokhi, E. Effects of cumin extract on oxLDL, paraoxanase 1 activity, FBS, total cholesterol, triglycerides, HDL-C, LDL-C, Apo A1, and Apo B in in the patients with hypercholesterolemia. Int. J. Health Sci. 8, 39 (2014). 
26. Haghighatfard, A., Andalib, S., Amini Faskhodi, M., Sadeghi, S., Ghaderi, A.H., Moradkhani, S., et al. Gene expression study of mitochondrial complex I in schizophrenia and paranoid personality disorder. World J. Biol. Psychiatry. 19, S133-S146 (2018).

27. Ardestani, A., Yazdanparast, R., Jamshidi, S. Therapeutic effects of Teucrium polium extract on oxidative stress in pancreas of streptozotocin-induced diabetic rats. J. Med. Food. 11, 525-532 (2018).

28. Gharaibeh, M.N., Elayan, H.H., Salhab, A.S. Hypoglycemic effects of Teucrium polium. J. Ethnopharmacol. 24, 93-99 (1988).

29. Alaee, M., Akbari, A., Karami, H., Salemi, Z., Amri, J., Panahi, M. Antidiabetic and protective effects of Scrophularia striata ethanolic extract on diabetic nephropathy via suppression of RAGE and S100A8 expression in kidney tissues of streptozotocin-induced diabetic rats. J. Basic. Clin. Physiol. Pharmacol. 31, (2020).

30. Azadmehr, A., Oghyanous, K.A., Hajiaghaee, R., Amirghofran, Z., Azadbakht, M. Antioxidant and neuroprotective effects of scrophularia striata extract against oxidative stress-induced neurotoxicity. Cell. Mol. Neurobiol. 33, 1135-1141 (2013).

31. Iskender, H., Dokumacioglu, E., Sen, T.M., Ince, I., Kanbay, Y., Saral, S. The effect of hesperidin and quercetin on oxidative stress, NF-KB and SIRT1 levels in a STZ-induced experimental diabetes model. Biomed. Pharmacother. 90, 500-508 (2017).

32. Anjaneyulu, M., Chopra, K. Quercetin, an anti-oxidant bioflavonoid, attenuates diabetic nephropathy in rats. Clin. Exp. Pharmacol. Physiol. 31, 244-248 (2004).

33. Yazdanparast, R., Ardestani, A., Jamshidi, S. Experimental diabetes treated with Achillea santolina: effect on pancreatic oxidative parameters. J. Ethnopharmacol. 112, 13-18 (2007).

34. Shanmugasundaram, E., Gopinath, K.L., Shanmugasundaram, K.R., Rajendran, V. Possible regeneration of the islets of Langerhans in streptozotocin-diabetic rats given Gymnema sylvestre leaf extracts. J. Ethnopharmacol. 30, 265-279 (1990).

35. Abdel Moneim, A., El-Feki, M., Salah, E. Effect of Nigella sativa, fish oil and gliclazide on alloxan diabetic rats 1-biochemical and histopathological studies. Journal-Egyptian German Society of Zoology. 23, 237-266 (1997).

36. Chakravarthy, B., Saroj, G., Gambhir, S., Gode, K. Pancreatic beta cell regeneration-a novel antidiabetic mechanism of Pterocarpus marsupium roxb. Indian J. Pharmacol. 12, 123 (1980).

37. Vargas-Guerrero, B., García-López, P.M., Martínez-Ayala, A.L., Domínguez-Rosales, J.A., Gurrola-Díaz, C.M. Administration of Lupinus albus gamma conglutin (CY) to n5 STZ rats augmented Ins-1 gene expression and pancreatic insulin content. Plant Foods Hum. Nutr. 69, 241-247 (2014).

38. Guo, S., Dai, C., Guo, M., Taylor, B., Harmon, J.S., Sander, M., et al. Inactivation of specific $\beta$ cell transcription factors in type 2 diabetes. J. Clin. Invest. 123, 3305-3316 (2013).

39. Talchai, C., Xuan, S., Lin, H.V., Sussel, L., Accili, D. Pancreatic $\beta$ cell dedifferentiation as a mechanism of diabetic $\beta$ cell failure. Cell. 150, 1223-1234 (2012). 
Figures

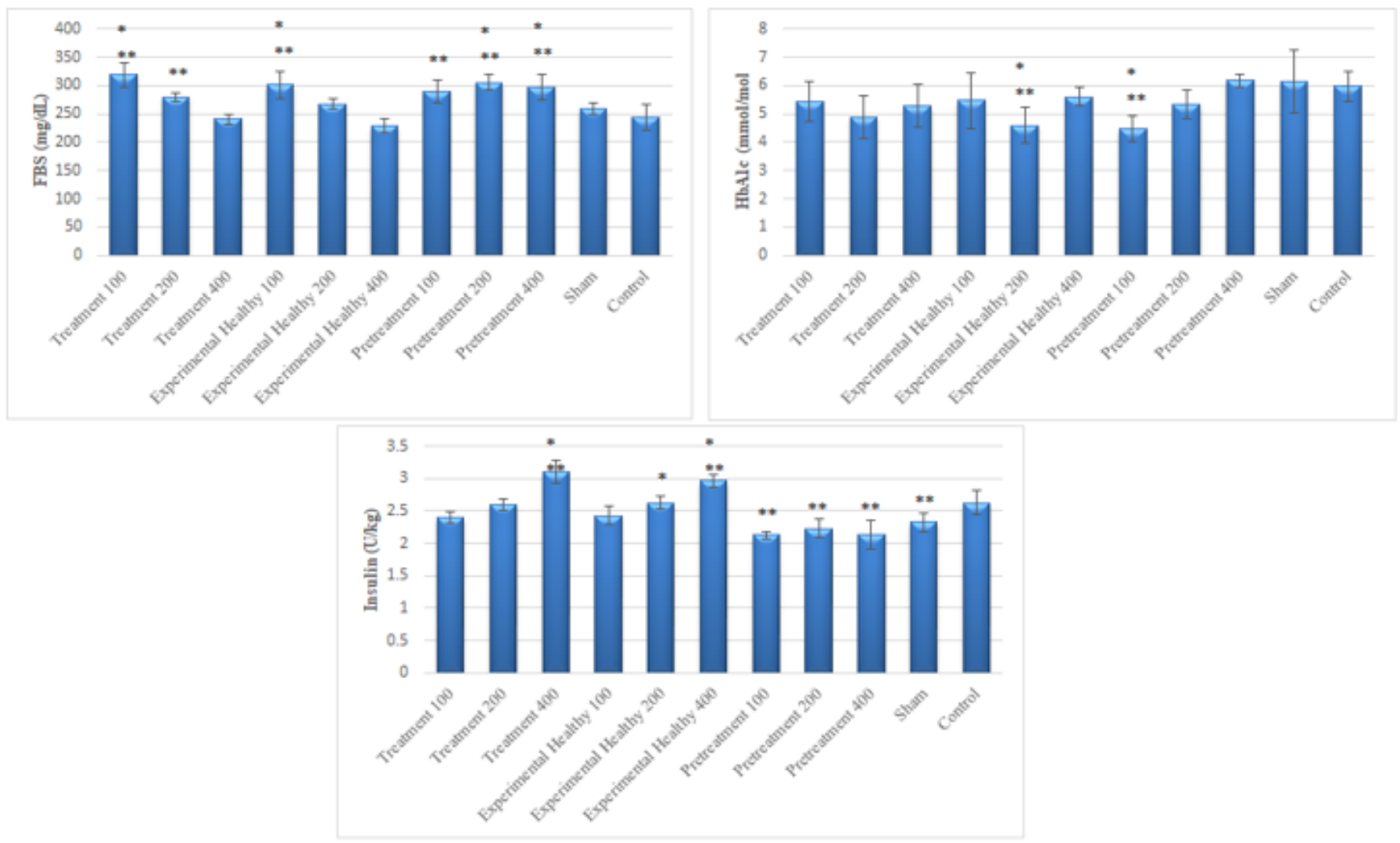

Figure 1

Data are expressed as the mean \pm SD; $n=6$ for each group. 100 , S. striata $100 \mathrm{mg} / \mathrm{kg} \mathrm{bw} ; 200$, S. striata $200 \mathrm{mg} / \mathrm{kg}$ bw; 400, S. striata $400 \mathrm{mg} / \mathrm{kg}$ bw. Significant differences compared to the Sham and Control groups are shown $\mathrm{P} \leq 0.5^{\star}$, and $\mathrm{P} \leq 0.05^{\star \star}$, respectively. ANOVA and Tukey's were applied to evaluate the data. 

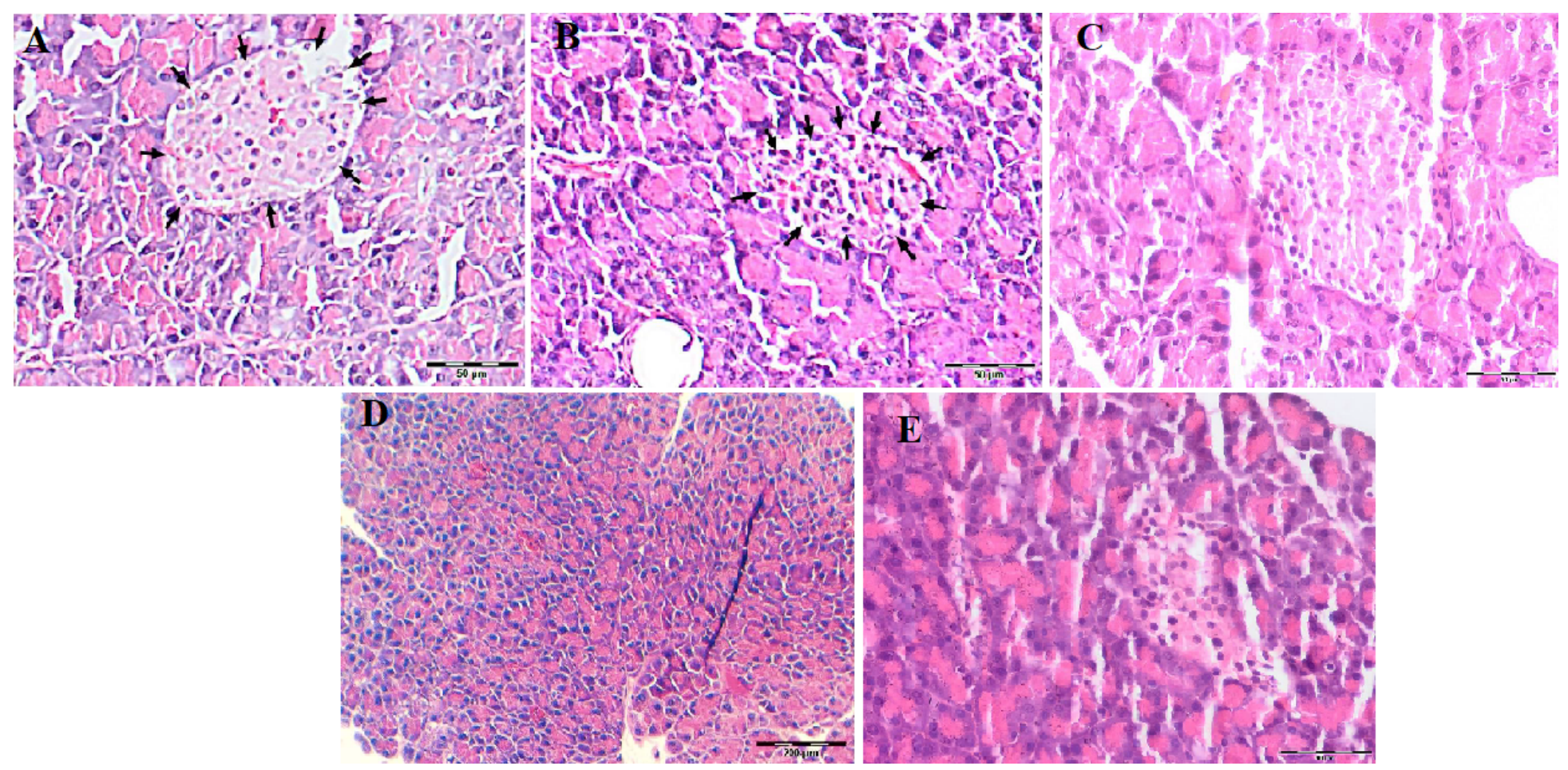

Figure 2

Legend not included with this version. 